\title{
PERBANDINGAN ANALISIS MULTI-TOWER DENGAN MODEL PENDEKATAN TERPISAH DAN MODEL UTUH
}

\author{
Raynaldo $^{1}$, Daniel Christianto ${ }^{2}$, dan Hadi Pranata ${ }^{3}$ \\ ${ }^{1}$ Program Studi Sarjana Teknik Sipil, Universitas Tarumanagara, Jl. Letjen S. Parman No.1 Jakarta \\ raynaldo.325160167@stu.untar.ac.id \\ ${ }^{2}$ Program Studi Sarjana Teknik Sipil, Universitas Tarumanagara, Jl. Letjen S. Parman No.1 Jakarta \\ danielc@ft.untar.ac.id \\ ${ }^{3}$ Program Studi Sarjana Teknik Sipil, Universitas Tarumanagara, Jl. Letjen S. Parman No.1 Jakarta \\ hadip@dtt.untar.ac.id
}

\begin{abstract}
In this study a multi-tower analysis comparison is conducted by comparing a separate approach model and a complete model. There are three approach models used for multi-tower building analysis which are model with unattached towers and podium (Type 1), model with a single tower connected to a cut podium (Type 2) and model with a single tower connected to a whole podium (Type 3). The approach model is analyzed with response spectrum response and the results were compared with the complete model analyzed with response spectrum and time history. The building structure model in this study uses a dual system. The analysis procedure is carried out based on SNI 1726:2012 with ETABS. Based on the analysis results, the type 2 model produces the building period that is the closest to the complete model building period. Type 1 model is not suitable for use as an approach model in multi-tower building analysis. The type 2 model is most ideal for use as an approach model. Type 3 model is a very conservative approach and can be used if more conservative design is desired. The tensile stress that occurs on the podium roof is insignificant in the multi-tower building under study.
\end{abstract}

Keywords: multi-tower; dynamic; response spectrum; time history

\begin{abstract}
ABSTRAK
Pada penelitian ini dilakukan perbandingan analisis multi-tower dengan model pendekatan terpisah dan model utuh. Ada tiga model pendekatan yang digunakan untuk analisis gedung multi-tower yaitu pemodelan menara dan podium terpisah (Tipe 1), pemodelan dengan menara tunggal terhubung pada podium terpotong (Tipe 2) dan pemodelan dengan menara tunggal terhubung pada podium utuh (Tipe 3). Model pendekatan dianalisis dengan prosedur respons spektrum dan hasilnya dibandingkan dengan model utuh yang dianalisis dengan respons spektrum dan riwayat waktu. Model struktur bangunan pada penelitian ini menggunakan sistem struktur ganda yaitu kombinasi antara sistem rangka pemikul momen dan sistem dinding geser. Prosedur analisis dilakukan berdasarkan SNI 1726:2012 dengan bantuan program ETABS. Berdasarkan hasil analisis, model tipe 2 menghasilkan periode bangunan yang paling mendekati dengan periode bangunan model utuh. Model tipe 1 kurang cocok untuk digunakan sebagai model pendekatan pada analisis bangunan multi-tower. Model tipe 2 paling ideal untuk digunakan sebagai model pendekatan. Model tipe 3 adalah model pendekatan yang sangat konservatif dan dapat digunakan jika ingin memperoleh desain yang konservatif. Tegangan tarik yang terjadi pada atap podium tidak signifikan pada bangunan multi-tower yang ditinjau.
\end{abstract}

Kata kunci: multi-tower; dinamis; respons spektrum; riwayat waktu

\section{PENDAHULUAN}

Secara struktural, perilaku dinamis pada bangunan multi-tower umumnya berbeda dengan gedung tinggi konvensional. Interaksi antar menara dapat mempengaruhi parameter masing-masing menara seperti gaya geser tingkat, simpangan antar lantai, momen guling tingkat dan lain-lain. Selain itu, respons masing-masing menara yang dapat berbeda fase dapat menimbulkan tegangan sejajar bidang yang besar pada diafragma lantai podium. Namun dalam prakteknya, analisis multi tower dengan model yang utuh biasanya dibandingkan lagi dengan model pendekatan. Hal ini dikarenakan parameter masing-masing substruktur sulit ditentukan dan banyaknya ketidakpastian dalam evaluasi struktur jika analisis dengan model utuh. Pada umumnya, ada tiga pendekatan yang 
seringkali digunakan untuk analisis gedung multi menara yaitu pemodelan menara dan podium terpisah, pemodelan dengan menara tunggal terhubung pada setengah podium dan pemodelan dengan menara tunggal terhubung pada podium utuh yang digambarkan pada Gambar 1. Pada penelitian ini, bangunan multi-tower akan dimodelkan dengan tiga pendekatan tersebut dengan analisis respons spektrum dan hasilnya akan dibandingkan dengan model utuh yang dianalisis dengan respons spektrum dan riwayat waktu untuk menghasilkan respons yang mendekati kenyataannya.

Pada penelitian ini, penulis akan membandingkan pemodelan multi-tower dengan tiga pendekatan yang dijelaskan sebelumnya dengan analisis respons spektrum dan hasilnya akan dibandingkan dengan model utuh yang dianalisis dengan respons spektrum dan riwayat waktu untuk menghasilkan respons yang mendekati kenyataannya. Selain itu gaya-gaya tarik yang terjadi pada diafragma lantai podium juga diperhitungkan pada model utuh dengan prosedur riwayat waktu pada penelitian ini. Penelitian ini bertujuan untuk membantu perencana untuk memilih model pendekatan terbaik yang cocok untuk digunakan untuk bangunan multi-tower selain menggunakan model utuh.
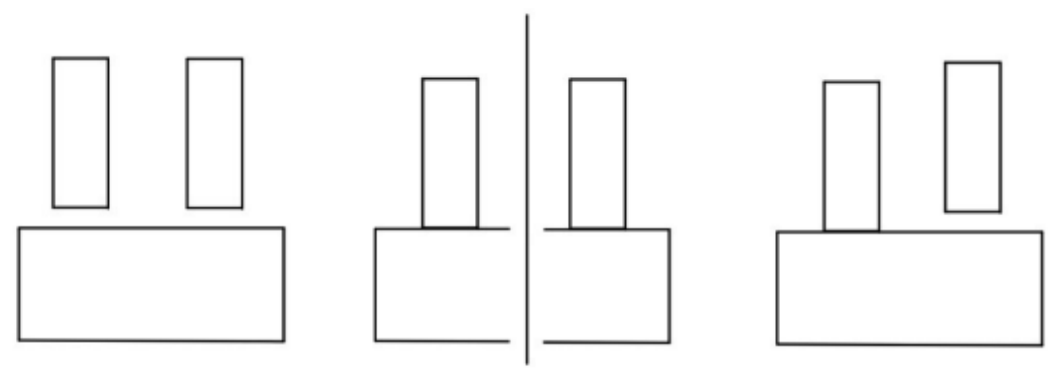

Gambar 1. Tiga model pendekatan yang digunakan

\section{Prosedur respons spektrum}

Respons spektrum adalah grafik/plot antara periode getar struktur $\mathrm{T}$ dan respons-respons maksimumnya pada suatu rasio redaman dan beban gempa tertentu. Respons masimum dapat berupa simpangan maksimum ,kecepatan maksimum dan percepatan maksimum suatu massa struktur dengan derajat kebebasan tunggal. Analisis respons spektrum menggunakan spektrum respons (bukan gerakan tanah) untuk menghitung respons maksimum di masing-masing ragam getar. Respon maksimum masing-masing ragam dikombinasikan dengan teknik statistik, seperti square root of the sum of the squares (SRSS) atau complete quadratic combination (CQC). (Chopra, 2011)

\section{Prosedur riwayat waktu}

Terdapat dua jenis prosedur metode riwayat waktu linier, yaitu modal superposition dan direct numerical integration. Modal superposition adalah prosedur yang sangat efisien dan akurat untuk analisis riwayat waktu. Integrasi tertutup pada persamaan modal digunakan untuk menghasilkan respons dengan mengasumsikan fungsi waktu bervariasi linier pada setiap tahapan waktu. Prosedur modal superposition menggunakan bentuk mode alami untuk mentransformasikan persamaan sistem derajat bebas majemuk coupled menjadi beberapa persamaan sistem derajat bebas tunggal yang uncoupled. Prosedur integrasi langsung menyelesaikan persamaan gerak coupled secara langsung, tanpa menggunakan bentuk mode alami. Persamaan coupled diintegrasikan secara numerik menggunakan satu dari beberapa teknik yang tersedia seperti metode Newmark linier. Prosedur tersebut membutuhkan pembentukan sistem yang eksplisit matriks redaman C. Prosedur integrasi langsung sangat sensitif terhadap tahapan waktu. Prosedur modal superposition umumnya lebih akurat dan efisien, namun prosedur integrasi langsung memiliki beberapa keuntungan sendiri yaitu redaman penuh yang menghubungkan mode dapat diperhitungkan. Pada penelitian ini, prosedur modal superposisi akan digunakan karena lebih akurat dan efisien. (Computer and Structures Inc, 2016)

Pada analisis riwayat waktu dengan tiga dimensi, gerak tanah harus terdiri dari sepasang komponen percepatan tanah horizontal $\left(u_{g}\right)$ dari rekaman gempa. Setiap pasang gerak tanah dibuat SRRSnya (Utara-Selatan dan TimurBarat). Nilai rata-rata respons setiap pasang gerak tanah yang teredam 5\% harus diskalakan agar lebih besar atau sama dengan respons spektrum desain, pada perioda 0,2 $T$ sampai 1,5 $T$. Respons individual harus dikalikan dengan satuan skalar berikut: (Badan Standarisasi Nasional, 2012)

- Parameter respons gaya dikalikan $I / R$

- Besaran simpangan antar lantai dikalikan $C d / R$ 
Riwayat waktu yang dipilih harus konsisten dengan parameter desain dan kondisinya. Faktor yang perlu dipertimbangkan dalam pemilihan yaitu: (FEMA 451B, 2007)

- Kondisi tektonik (subduksi, kerak dangkal dan lainnya)

- Magnitudo gempa dan tipe patahan

- Jarak dari lokasi rekaman ke patahan

- Kondisi situs pada daerah rekaman

- Spektra respons gerakan (faktor skala lebih baik kurang dari dua)

- Durasi guncangan yang kuat

Proses penskalaan dilakukan dalam dua tahap yaitu: (FEMA 451B, 2007)

- Penskalaan sederhana yaitu menskalakan gerakan berdasarkan suatu faktor untuk mencocokan riwayat waktu dengan spektrum target, dengan faktor skala tidak lebih dari dua. Diinginkan agar rata-rata spektra dari riwayat waktu secara visual cocok dengan spektra target.

- Spectrum matching yaitu perubahan dilakukan pada domain waktu atau domain frekuensi untuk mengubah karakteristik gerakan. Dalam spectrum matching perlu diperhatikan agar:

- Mempertahankan karakter domain waktu dari riwayat waktu

- Memulai dengan riwayat waktu yang memiliki bentuk spektrum yang mirip dengan target spectrum.

- Terlebih dahulu menskalakan riwayat waktu sampai mendekati target spektrum sebelum perubahan berikutnya.

Dalam spectrum matching ada 2 jenis pendekatan yaitu:

- Pendekatan domain waktu. Matching dilakukan dengan menambah atau mengurangi gelombang kecil dengan durasi yang terbatas pada riwayat waktu awal. Pada umumnya pendekatan ini akan menghasilkan hasil spektrum yang cocok dengan spektrum tertarget. Namun sebaiknya bentuk spektrum riwayat waktu mirip dengan respons tertarget. (Abrahamson, 1992)

- Pendekatan domain frekuensi. Mengubah amplitudo Fourier dengan tetap mempertahankan fasenya. Pendekatan ini tidak selalu menghasilkan hasil yang mendekati spektrum tertarget. (Bolt dan Gregor, 1993)

Pada penelitian ini penulis akan menggunakan program Seismomatch untuk menskalakan riwayat waktu agar spektrumnya sesuai dengan spektrum tertarget. Seismomatch mencocokkan spektrum berdasarkan prosedur domain waktu menggunakan algoritma gelombang. (Seismosoft, 2018)

\section{METODE PENELITIAN}

Pada penelitian ini, pemodelan dan analisis dilakukan dengan menggunakan program ETABS. Penulis akan memodelkan tiga model pendekatan yaitu pemodelan menara dan podium terpisah, pemodelan dengan menara tunggal terhubung pada setengah podium dan pemodelan dengan menara tunggal terhubung pada podium utuh dan satu model utuh. Model pendekatan akan dianalisis menggunakan prosedur analisis respons spektrum yang lebih umum digunakan oleh perencana-perencana, sedangkan model utuh akan dianalisis menggunakan prosedur respons spektrum dan juga analisis riwayat waktu.

\section{Pemodelan}

Pemodelan pada penelitian ini dilakukan secara tiga dimensi dengan bantuan program ETABS. Model bangunan terdiri dari podium dengan tiga menara yang identik. Model bangunan tersebut terdiri dari tiga tingkat pada podium dan 36 tingkat pada masing-masing menara. Model struktur bangunan pada penelitian ini menggunakan sistem struktur ganda yaitu kombinasi antara sistem rangka pemikul momen dan sistem dinding geser. Model 3D tipe 1 yaitu pemodelan menara dan podium terpisah ditunjukkan pada Gambar 2. Model 3D tipe 2 yaitu pemodelan dengan menara tunggal terhubung pada podium terpotong ditunjukkan pada Gambar 3. Model 3D tipe 3 yaitu pemodelan dengan menara tunggal terhubung pada podium utuh ditunjukkan pada Gambar 4 dan Gambar 5 . 
Perbandingan Analisis Multi-Tower Dengan Model

Raynaldo, et al.

Pendekatan Terpisah Dan Model Utuh

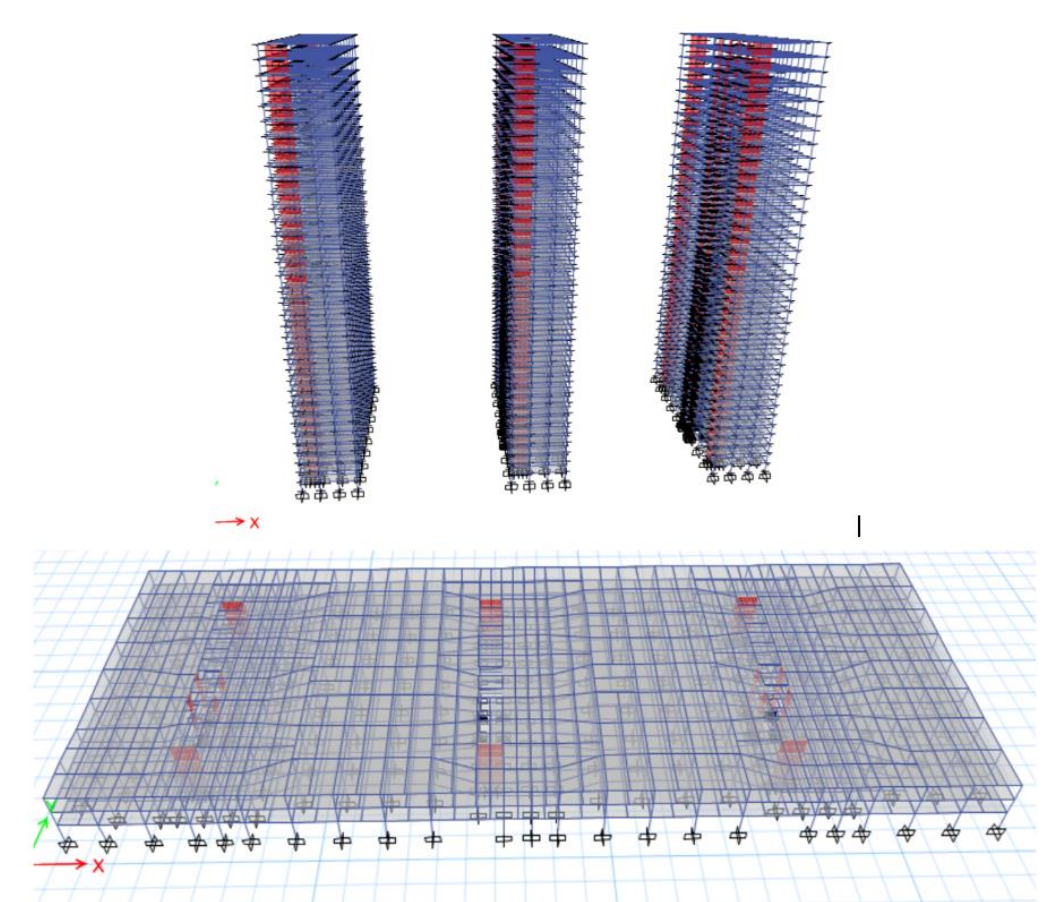

Gambar 2. Model pendekatan tipe 1

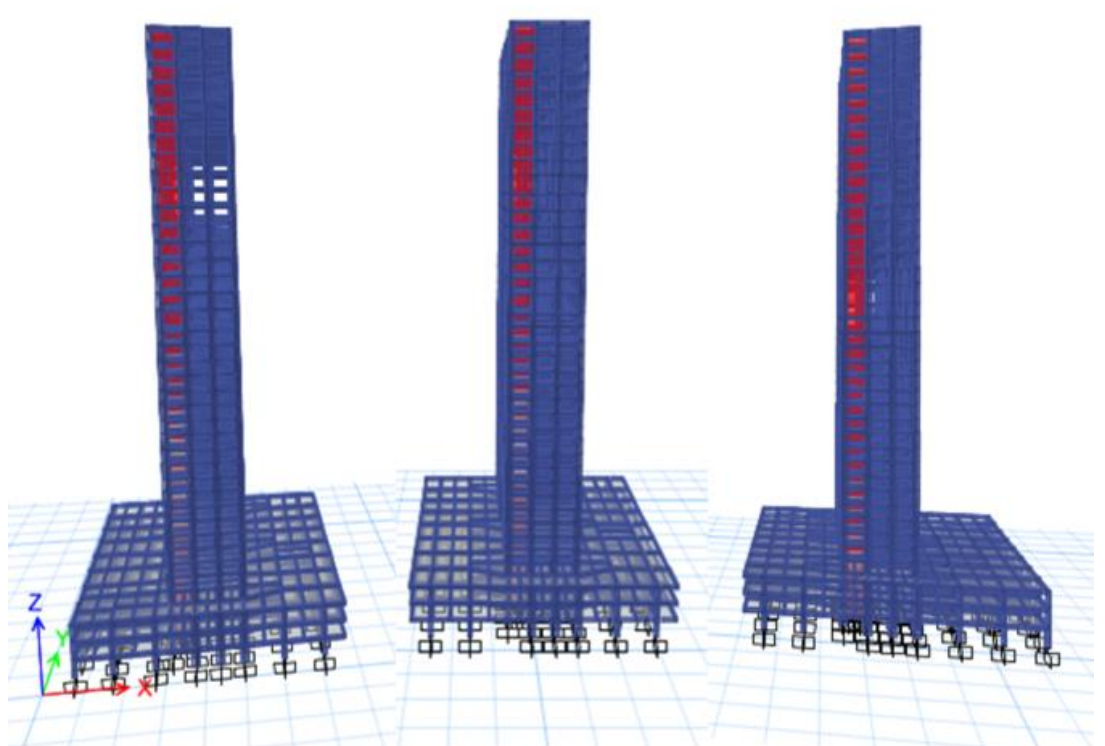

Gambar 3. Model pendekatan tipe 2 

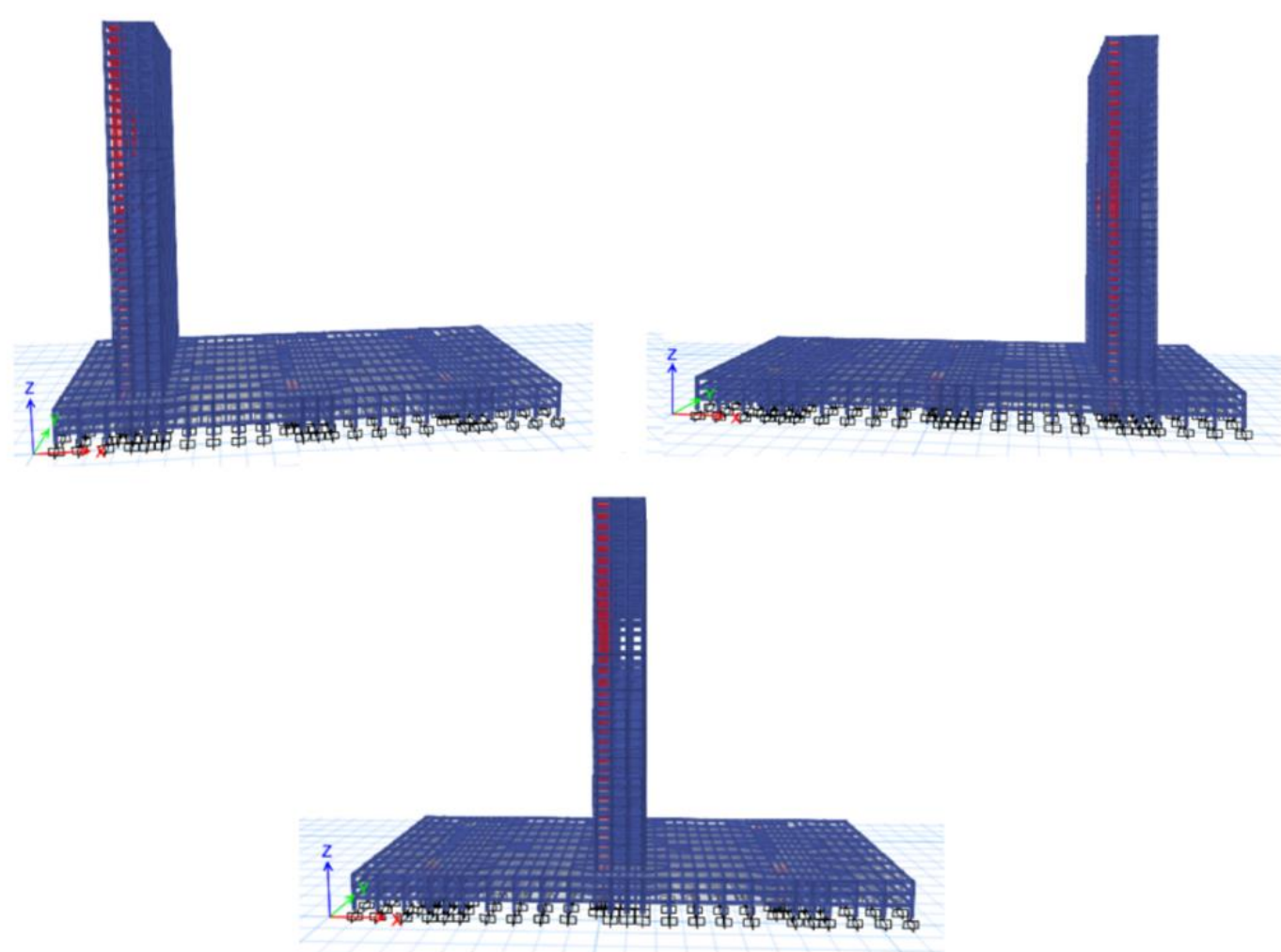

Gambar 4. Model pendekatan tipe 3

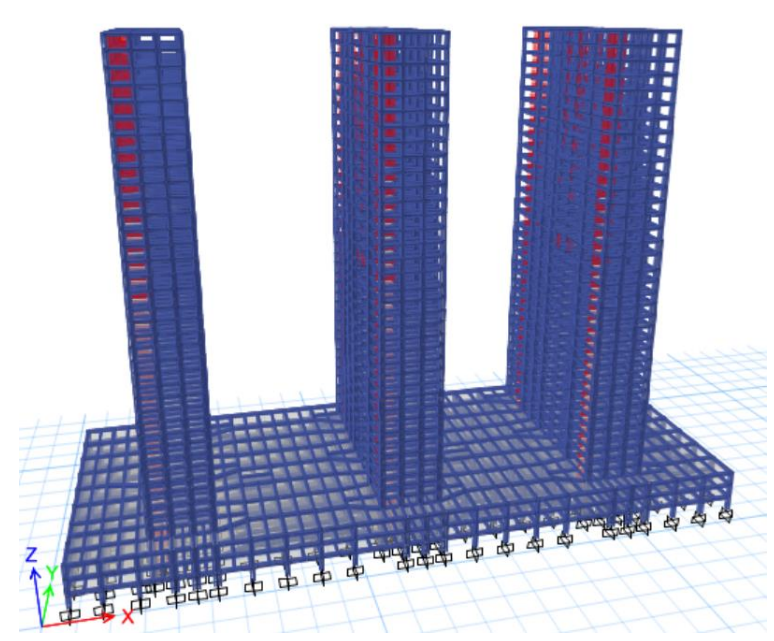

Gambar 5. Model utuh

\section{Prosedur analisis}

\section{Prosedur respons spektrum}

Untuk menentukan fungsi respons spektrum desain maka diperlukan parameter percepatan gempa pada perioda pendek (Ss) dan parameter percepatan gempa pada perioda satu detik (S1). Berdasarkan PUSKIM, daerah Tangerang memiliki nilai Ss dan S1 sebesar 0,686 g dan 0,302 g. Hasil grafik respons spektrum desain dan parameter-parameter respons spektrum yang didapat puskim.pu.go.id/Aplikasi/desain_spektra_indonesia_2011 ditampilkan pada Tabel 1. 
Tabel 1. Parameter desain respons spektrum

\begin{tabular}{cc}
\hline Parameter & Nilai \\
\hline PGA $(g)$ & 0,363 \\
$\mathrm{~S}_{\mathrm{S}}(\mathrm{g})$ & 0,686 \\
$\mathrm{~S}_{1}(\mathrm{~g})$ & 0,302 \\
$\mathrm{~F}_{\mathrm{A}}$ & 1,329 \\
$\mathrm{~F}_{\mathrm{V}}$ & 2,792 \\
$\mathrm{PSA}(\mathrm{g})$ & 0,367 \\
$\mathrm{~S}_{\mathrm{MS}}(\mathrm{g})$ & 0,911 \\
$\mathrm{~S}_{\mathrm{M} 1}(\mathrm{~g})$ & 0,843 \\
$\mathrm{~S}_{\mathrm{DS}}(\mathrm{g})$ & 0,607 \\
$\mathrm{~S}_{\mathrm{D} 1}(\mathrm{~g})$ & 0,562 \\
$\mathrm{~T}_{0}($ detik$)$ & 0,185 \\
$\mathrm{~T}_{\mathrm{S}}($ detik$)$ & 0,925 \\
\hline
\end{tabular}

\section{Prosedur Riwayat waktu}

Pemilihan catatan gempa menggunakan situs https://ngawest2.berkeley.edu/. Secara umum struktur geologi aktif Jawa didominasi oleh sesar geser dan sesar naik. (Tim Pusat Studi Gempa Nasional, 2017)

Dalam pemilihan catatan gempa, parameter respons spektrum tertarget dimasukkan pada situs sehingga dalam pencarian akan dicari catatan gempa yang memiliki respons spektrum yang mendekati spektrum tertarget. Faktor skala yang disarankan berkisaran dari 0,5 sampai 2, namun karena kurangnya catatan gempa yang diperoleh pada kisaran tersebut, maka menggunakan faktor skala 0,3 sampai 3 pada pencarian.

Berdasarkan keterangan yang disebutkan sebelumnya, maka parameter pencarian catatan dimasukkan pada situs dan didapat riwayat waktu pada 7 peristiwa gempa yang berbeda. Parameter pencarian tersebut diperlihatkan pada Gambar 6 dan hasil pencarian catatan gempa diringkas dalam Tabel 2.

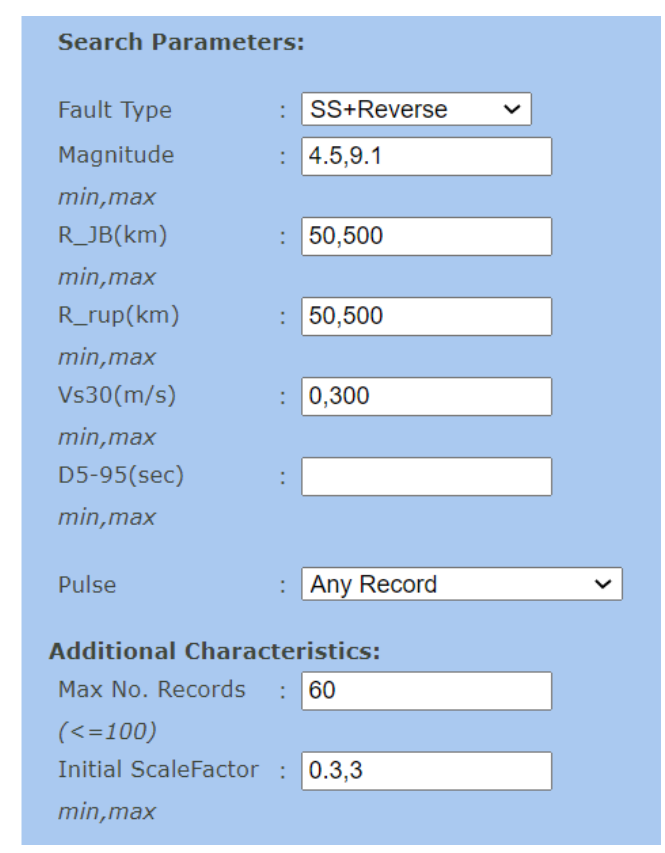

Gambar 6. Parameter pencarian catatan gempa (Sumber: PEER) 
Tabel 2. Hasil pencarian catatan gempa

\begin{tabular}{cccccc}
\hline Nama Gempa & $\begin{array}{c}\text { Faktor } \\
\text { Skala }\end{array}$ & Tahun & Nama Stasiun & Magnitudo & Mekanisme \\
\hline "Coalinga-01" & 2,94 & 1983 & "Parkfield - Cholame 8W" & 6,36 & Reverse \\
"Taiwan SMART1(45)" & 1,88 & 1986 & $\begin{array}{c}\text { "SMART1 O02" } \\
\text { "San Bernardino - E \& }\end{array}$ & 7,30 & Reverse \\
"Landers" & 1,96 & 1992 & $\begin{array}{c}\text { Hospitality" } \\
\text { "Indio - Riverside Co Fair } \\
\text { Grnds" }\end{array}$ & 6,46 & Strike slip \\
"Big Bear-01" & 2,92 & 1992 & "HIK" & 6,90 & Strike slip \\
"Kobe_Japan" & 2,76 & 1995 & "Ambarli" & 7,51 & Strike slip \\
"Kocaeli_Turkey" & 0,95 & 1999 & "CHY107" & 7,62 & Reverse Oblique \\
"Chi-Chi_Taiwan" & 1,36 & 1999 &
\end{tabular}

Setelah pencarian catatan waktu, penskalaan dilakukan dengan bantuan program SeismoMatch dimana suatu faktor skala diberikan terlebih dahulu pada riwayat waktu sampai mendekati target spektrum lalu dilakukan spectral matching dengan prosedur time domain.

\section{HASIL DAN PEMBAHASAN}

\section{Periode bangunan}

Berdasarkan hasil analisis dari ETABS, maka diperoleh periode bangunan untuk setiap model analisis. Perbandingan periode bangunan arah $\mathrm{x}$ dan arah y pada setiap model dengan model utuh ditunjukkan pada Tabel 3.

Tabel 3. Perbandingan periode bangunan arah $\mathrm{x}$ dan y pada setiap model analisis dengan model utuh

\begin{tabular}{cccccc}
\hline \multirow{2}{*}{ Model } & Tipe & \multicolumn{2}{c}{ Periode Bangunan (detik) } & \multicolumn{2}{c}{ Selisih dengan Model Utuh (\%) } \\
\cline { 3 - 6 } & & Translasi X & Translasi Y & Translasi X & Translasi Y \\
\hline \multirow{2}{*}{1} & Tower & 3,466 & 3,250 & $-8,789$ & $-5,933$ \\
& Podium & 0,227 & 0,316 & $-94,026$ & -9.854 \\
\multirow{2}{*}{2} & 2A & 3,808 & 3,455 & 0,211 & 0,000 \\
& 2B & 3,825 & 3,473 & 0,658 & 0,521 \\
& 2C & 3,795 & 3,452 & $-0,132$ & $-0,087$ \\
3 & 3A & 3,720 & 3,411 & $-2,105$ & $-1,274$ \\
& 3B & 3,723 & 3,375 & $-2,026$ & $-2,315$ \\
\multirow{2}{*}{ Model Utuh } & 3C & 3,721 & 3,414 & $-2,079$ & $-1,187$ \\
\hline
\end{tabular}

\section{Gaya geser}

Perbandingan gaya geser dinamis pada setiap menara pada model pendekatan dengan model utuh dengan prosedur respons spektrum ditunjukkan pada Tabel 4 dan Tabel 5. Perbandingan gaya geser desain pada setiap menara pada model pendekatan dengan model utuh dengan prosedur respons spektrum ditunjukkan pada Tabel 6 dan Tabel 7. Perbandingan gaya geser dinamis murni pada setiap menara pada model pendekatan dengan model utuh dengan prosedur riwayat waktu ditunjukkan pada Tabel 8 dan Tabel 9. Perbandingan gaya geser desain pada setiap menara pada model pendekatan dengan model utuh dengan prosedur riwayat waktu ditunjukkan pada Tabel 10 dan Tabel 11. 
Tabel 4. Tabel perbandingan gaya geser dinamis murni pada dasar menara antara model pendekatan dan model utuh respons spektrum

\begin{tabular}{cccccccc}
\hline \multicolumn{7}{c}{ Gaya Geser Dinamis Murni pada Dasar Menara } \\
\hline \multirow{2}{*}{ Model } & \multirow{2}{*}{ Tower } & \multicolumn{2}{c}{ Gaya Geser (Ton) } & \multicolumn{2}{c}{$\begin{array}{c}\text { Model Utuh Respons } \\
\text { Spektrum (Ton) }\end{array}$} & \multicolumn{2}{c}{ Selisih (\%) } \\
\cline { 3 - 8 } & & X & Y & X & Y & X & Y \\
\cline { 3 - 8 } & A & 544,0103 & 542,2562 & 563,5218 & 587,6414 & $-3,46242$ & $-7,72328$ \\
& B & 544,0103 & 542,2562 & 561,5014 & 585,746 & $-3,11506$ & $-7,42469$ \\
& C & 544,0103 & 542,2562 & 560,4957 & 583,9552 & $-2,94122$ & $-7,14079$ \\
& A & 557,52 & 556,86 & 563,5218 & 587,6414 & $-1,06505$ & $-5,23813$ \\
& B & 555,9581 & 556,1387 & 561,5014 & 585,746 & $-0,98723$ & $-5,05463$ \\
& C & 560,7618 & 560,0465 & 560,4957 & 583,9552 & 0,047476 & $-4,09427$ \\
& A & 594,2929 & 572,3353 & 563,5218 & 587,6414 & 5,460499 & $-2,60467$ \\
& B & 593,9896 & 587,2461 & 561,5014 & 585,746 & 5,785952 & 0,256101 \\
& C & 594,3152 & 573,9584 & 560,4957 & 583,9552 & 6,033855 & $-1,71191$ \\
\hline
\end{tabular}

Tabel 5. Tabel perbandingan gaya geser dinamis murni pada dasar podium antara model pendekatan dan model utuh respons spektrum

\begin{tabular}{cccccccc}
\hline \multicolumn{7}{c}{ Gaya Geser Dinamis Murni pada Dasar Podium } \\
\hline \multirow{2}{*}{ Model } & Tipe & \multicolumn{2}{c}{ Gaya Geser (Ton) } & \multicolumn{2}{c}{$\begin{array}{c}\text { Model Utuh Respons } \\
\text { Spektrum (Ton) }\end{array}$} & \multicolumn{2}{c}{ Selisih (\%) } \\
\cline { 3 - 8 } & & X & Y & X & Y & X & Y \\
\hline 1 & - & 6105,9 & 6082,68 & 2167,306 & 2264,6443 & 181,7277 & 168,5932 \\
2 & - & 2018,018 & 2071,32 & 2167,306 & 2264,6443 & $-6,88819$ & $-8,53664$ \\
& 3A & 2574,486 & 2770,68 & 2167,306 & 2264,6443 & 18,78738 & 22,34503 \\
3 & 3B & 2573,334 & 2629,109 & 2167,306 & 2264,6443 & 18,73424 & 16,09367 \\
& 3C & 2574,056 & 2682,627 & 2167,306 & 2264,6443 & 18,76753 & 18,4569 \\
\hline
\end{tabular}

Tabel 6. Tabel perbandingan gaya geser desain pada dasar menara antara model pendekatan dan model utuh respons spektrum

\begin{tabular}{cccccccc}
\hline \multicolumn{7}{c}{ Gaya Geser Desain pada Dasar Menara } \\
\hline \multirow{2}{*}{ Model } & Tower & \multicolumn{2}{c}{ Gaya Geser (Ton) } & \multicolumn{2}{c}{$\begin{array}{c}\text { Model Utuh Respons } \\
\text { Spektrum (Ton) }\end{array}$} & \multicolumn{2}{c}{ Selisih (\%) } \\
\cline { 3 - 8 } & & X & Y & X & Y & X & Y \\
\cline { 3 - 8 } & A & 790,03 & 790,03 & 1059,86 & 1059,86 & $-25,459$ & $-25,459$ \\
1 & B & 790,03 & 790,03 & 1059,86 & 1059,86 & $-25,459$ & $-25,459$ \\
& C & 790,03 & 790,03 & 1059,86 & 1059,86 & $-25,459$ & $-25,459$ \\
& A & 1054,73 & 1054,73 & 1059,86 & 1059,86 & $-0,48403$ & $-0,48403$ \\
2 & B & 1053,99 & 1053,99 & 1059,86 & 1059,86 & $-0,55385$ & $-0,55385$ \\
& C & 1080,98 & 1080,98 & 1059,86 & 1059,86 & 1,992716 & 1,992716
\end{tabular}




\begin{tabular}{cccccccc}
\hline \multicolumn{7}{c}{ Gaya Geser Desain pada Dasar Menara } \\
Model & Tower & \multicolumn{2}{c}{ Gaya Geser (Ton) } & \multicolumn{2}{c}{$\begin{array}{c}\text { Model Utuh Respons } \\
\text { Spektrum (Ton) }\end{array}$} & \multicolumn{2}{c}{ Selisih (\%) } \\
\cline { 3 - 8 } & & $\mathrm{X}$ & $\mathrm{Y}$ & $\mathrm{X}$ & $\mathrm{Y}$ & $\mathrm{X}$ & $\mathrm{Y}$ \\
\hline \multirow{3}{*}{3} & $\mathrm{~A}$ & 1591 & 1591 & 1059,86 & 1059,86 & 50,11417 & 50,11417 \\
& $\mathrm{~B}$ & 1591 & 1591 & 1059,86 & 1059,86 & 50,11417 & 50,11417 \\
& $\mathrm{C}$ & 1591 & 1591 & 1059,86 & 1059,86 & 50,11417 & 50,11417 \\
\hline
\end{tabular}

Tabel 7. Tabel perbandingan gaya geser desain pada dasar podium antara model pendekatan dan model utuh respons spektrum

\begin{tabular}{cccccccc}
\hline \multicolumn{7}{c}{ Gaya Geser Desain pada Dasar Podium } \\
\hline \multirow{2}{*}{ Model } & Tipe & \multicolumn{2}{c}{ Gaya Geser (Ton) } & \multicolumn{2}{c}{$\begin{array}{c}\text { Model Utuh Respons } \\
\text { Spektrum (Ton) }\end{array}$} & \multicolumn{2}{c}{ Selisih (\%) } \\
\cline { 3 - 8 } & & X & Y & X & Y & X & Y \\
\cline { 2 - 8 } & - & 6105,9 & 6082,68 & 3193,85 & 3193,85 & 91,17679 & 90,44977 \\
2 & - & 3203,69 & 3203,69 & 3193,85 & 3193,85 & 0,308092 & 0,308092 \\
& 3A & 4793,45 & 4793,45 & 3193,85 & 3193,85 & 50,08375 & 50,08375 \\
3 & 3B & 4793,45 & 4793,45 & 3193,85 & 3193,85 & 50,08375 & 50,08375 \\
& 3C & 4793,45 & 4793,45 & 3193,85 & 3193,85 & 50,08375 & 50,08375 \\
\hline
\end{tabular}

Tabel 8. Tabel perbandingan gaya geser dinamis murni pada dasar menara antara model pendekatan dan model utuh riwayat waktu rata-rata

\begin{tabular}{cccccccc}
\hline \multicolumn{7}{c}{ Gaya Geser Dinamis Murni pada Dasar Menara } \\
\hline \multirow{2}{*}{ Model } & \multirow{2}{*}{ Tower } & \multicolumn{2}{c}{ Gaya Geser (Ton) } & \multicolumn{2}{c}{$\begin{array}{c}\text { Model Utuh Riwayat Waktu } \\
\text { (Rata-rata) (Ton) }\end{array}$} & \multicolumn{2}{c}{ Selisih (\%) } \\
\cline { 3 - 8 } & & X & Y & X & Y & X & Y \\
\cline { 3 - 8 } & A & 544,0103 & 542,2562 & 316,5762 & 338,849986 & 71,84181 & 60,0284 \\
1 & B & 544,0103 & 542,2562 & 315,2193 & 339,99 & 72,58156 & 59,49181 \\
& C & 544,0103 & 542,2562 & 313,4548 & 341,136814 & 73,55302 & 58,95564 \\
& A & 557,52 & 556,86 & 316,5762 & 338,849986 & 76,10925 & 64,33821 \\
& B & 555,9581 & 556,1387 & 315,2193 & 339,99 & 76,37187 & 63,57502 \\
& C & 560,7618 & 560,0465 & 313,4548 & 341,136814 & 78,89717 & 64,17064 \\
& A & 594,2929 & 572,3353 & 316,5762 & 338,849986 & 87,72506 & 68,90522 \\
& B & 593,9896 & 587,2461 & 315,2193 & 339,99 & 88,43696 & 72,72452 \\
& C & 594,3152 & 573,9584 & 313,4548 & 341,136814 & 89,60155 & 68,24874 \\
\hline
\end{tabular}


Tabel 9. Tabel perbandingan gaya geser dinamis murni pada dasar podium antara model pendekatan dan model utuh riwayat waktu rata-rata

Gaya Geser Dinamis Murni pada Dasar Podium

\begin{tabular}{cccccccc}
\hline \multirow{2}{*}{ Model } & Tipe & \multicolumn{2}{c}{ Gaya Geser (Ton) } & \multicolumn{2}{c}{$\begin{array}{c}\text { Model Utuh Riwayat Waktu } \\
\text { (Rata-rata) (Ton) }\end{array}$} & \multicolumn{2}{c}{ Selisih (\%) } \\
\cline { 3 - 8 } & & X & Y & X & Y & X & Y \\
\hline 1 & - & 6105,9 & 6082,68 & 1395,579 & 1437,99547 & 337,5174 & 322,9972 \\
2 & - & 2018,018 & 2071,32 & 1395,579 & 1437,99547 & 44,60077 & 44,04216 \\
& A & 2574,486 & 2770,68 & 1395,579 & 1437,99547 & 84,47441 & 92,67653 \\
3 & B & 2573,334 & 2629,109 & 1395,579 & 1437,99547 & 84,39189 & 82,8315 \\
& C & 2574,056 & 2682,627 & 1395,579 & 1437,99547 & 84,44358 & 86,55326 \\
\hline
\end{tabular}

Tabel 10. Tabel perbandingan gaya geser desain pada dasar menara antara model pendekatan dan model utuh riwayat waktu rata-rata

\begin{tabular}{cccccccc}
\hline \multirow{2}{*}{ Model } & \multirow{7}{c}{ Gaya Geser Desain pada Dasar Menara } \\
& Tower & \multicolumn{2}{c}{ Gaya Geser (Ton) } & \multicolumn{2}{c}{ Model Utuh Riwayat } \\
& & & & Waktu (Rata-rata) (Ton) & \multicolumn{2}{c}{ Selisih (\%) } \\
\cline { 3 - 8 } & & X & Y & X & Y & X & Y \\
\hline \multirow{3}{*}{1} & A & 790,03 & 790,03 & 1040,64 & 1040,64 & $-24,0823$ & $-24,0823$ \\
& B & 790,03 & 790,03 & 1040,64 & 1040,64 & $-24,0823$ & $-24,0823$ \\
& C & 790,03 & 790,03 & 1040,64 & 1040,64 & $-24,0823$ & $-24,0823$ \\
& A & 1054,73 & 1054,73 & 1040,64 & 1040,64 & 1,353974 & 1,353974 \\
& B & 1053,99 & 1053,99 & 1040,64 & 1040,64 & 1,282864 & 1,282864 \\
& C & 1080,98 & 1080,98 & 1040,64 & 1040,64 & 3,876461 & 3,876461 \\
& A & 1591 & 1591 & 1040,64 & 1040,64 & 52,88669 & 52,88669 \\
& B & 1591 & 1591 & 1040,64 & 1040,64 & 52,88669 & 52,88669 \\
& C & 1591 & 1591 & 1040,64 & 1040,64 & 52,88669 & 52,88669 \\
\hline
\end{tabular}

Tabel 11. Tabel perbandingan gaya geser desain pada dasar podium antara model pendekatan dan model utuh riwayat waktu rata-rata

\begin{tabular}{cccccccc}
\hline \multicolumn{7}{c}{ Gaya Geser Desain pada Dasar Podium } \\
\hline \multirow{2}{*}{ Model } & Tower & \multicolumn{2}{c}{ Gaya Geser (Ton) } & $\begin{array}{c}\text { Model Utuh Riwayat } \\
\text { Waktu (Rata-rata) (Ton) }\end{array}$ & \multicolumn{2}{c}{ Selisih (\%) } \\
\cline { 3 - 8 } & & X & Y & X & Y & X & Y \\
\hline 1 & - & 6105,9 & 6082,68 & 3136,08 & 3136,08 & 94,69848 & 93,95806 \\
2 & - & 3203,69 & 3203,69 & 3136,08 & 3136,08 & 2,155876 & 2,155876 \\
& A & 4793,45 & 4793,45 & 3136,08 & 3136,08 & 52,84846 & 52,84846 \\
3 & B & 4793,45 & 4793,45 & 3136,08 & 3136,08 & 52,84846 & 52,84846 \\
& C & 4793,45 & 4793,45 & 3136,08 & 3136,08 & 52,84846 & 52,84846 \\
\hline
\end{tabular}




\section{Tegangan tarik}

Tegangan tarik tidak dapat dilihat jika model utuh dianalisis dengan prosedur respons spektrum. Namun jika model dianalisis dengan prosedur riwayat waktu maka dapat terlihat terdapat tegangan tarik yang terjadi pada atap podium yang disebabkan oleh interaksi antar menara yang berbeda fase. Tegangan tarik yang terjadi pada diafragma di atap podium tidak lebih besar dari 0,5 MPa pada masing-masing catatan gempa.

\section{KESIMPULAN DAN SARAN}

\section{Kesimpulan}

Berdasarkan simulasi dan analisis yang telah dilakukan pada model-model pendekatan dan model utuh, dapat disimpulkan hal-hal berikut:

1. Pada pemodelan Tipe 1, periode getar menara dan podium dari analisis lebih kecil daripada model utuh. Hal ini menunjukkan struktur lebih kaku ketika dianalisis dengan model Tipe 1 karena menara dan podium dianalisis secara terpisah, dan interaksi menara dan podium diabaikan. Model Tipe 2 menghasilkan periode bangunan yang paling mendekati dengan periode bangunan model utuh dengan selisih berkisar dari 0,132\% sampai $0,658 \%$. Model Tipe 3 menghasilkan periode bangunan yang sedikit lebih kecil daripada periode bangunan model utuh dengan selisih berkisar dari $1,187 \%$ sampai $2,315 \%$.

2. Pada model Tipe 1 gaya geser dinamis dan gaya geser desain pada dasar menara lebih kecil daripada model utuh yang dianalisis dengan respons spektrum dengan selisih sampai -7,72\% untuk gaya geser dinamis murni dan $-25,46 \%$ untuk gaya geser desain. Sedangkan gaya geser dinamis dan gaya geser desain pada dasar podium jauh lebih besar daripada model utuh baik dengan prosedur respons spektrum maupun riwayat waktu. Berdasarkan hasil tersebut, penulis menyimpulkan model pendekatan Tipe 1 kurang cocok untuk digunakan sebagai model pendekatan pada analisis bangunan multi-tower.

3. Pada model Tipe 2 gaya geser dinamis murni pada dasar menara mendekati model utuh pada prosedur respons spektrum dengan selisih dari $-5,23 \%$ hingga $0,047 \%$. Selain itu gaya geser yang digunakan untuk desain pada dasar menara mendekati model utuh pada prosedur respons spektrum (dari $-0,484 \%$ hingga $1,99 \%$ ) dan prosedur riwayat waktu (hingga 3,88\%). Gaya geser dinamis pada dasar podium lebih kecil hingga $8,53 \%$ daripada model utuh dengan prosedur respons spektrum, namun lebih besar daripada model utuh dengan prosedur riwayat waktu hingga 44,6\%. Gaya geser desain pada dasar podium mendekati model utuh dengan prosedur respons spektrum $(0,308 \%)$ dan riwayat waktu $(2,16 \%)$. Dengan hasil tersebut penulis menyimpulkan model pendekatan Tipe 2 paling ideal untuk digunakan sebagai model pendekatan.

4. Pada model Tipe 3 gaya geser dinamis murni pada dasar menara mendekati model utuh pada prosedur respons spektrum dengan selisih dari $-2,6 \%$ hingga 6,03\%. Namun gaya geser yang digunakan untuk desain pada dasar menara lebih besar daripada model utuh pada prosedur respons spektrum $(50,1 \%)$ dan prosedur riwayat waktu (52.8\%). Gaya geser dinamis pada dasar podium lebih besar hingga 18,8\% daripada model utuh dengan prosedur respons spektrum dan lebih besar hingga 92,7\% daripada model utuh dengan prosedur riwayat waktu. Gaya geser desain pada dasar podium juga melebihi model utuh dengan prosedur respons spektrum $(50,1 \%)$ dan riwayat waktu $(52,8 \%)$. Dengan hasil tersebut penulis menyimpulkan model pendekatan Tipe 3 adalah model pendekatan yang sangat konservatif dan dapat digunakan jika ingin memperoleh desain yang konservatif.

5. Jika model dianalisis dengan prosedur riwayat waktu maka dapat terlihat terdapat tegangan tarik yang terjadi pada atap podium yang disebabkan oleh interaksi antar menara yang berbeda fase. Namun tegangan tarik yang terjadi tidak signifikan.

\section{Saran}

Adapun saran dari peneliti untuk penelitian yang lebih lanjut tentang analisis multitower yaitu:

1. Dapat dilakukan penelitian dengan tinggi menara yang berbeda sehingga efek tegangan tarik akibat menara yang berbeda tinggi dapat diamati.

2. Perlu dilakukan pencarian catatan gempa dengan respons spektrum yang lebih mendekati bentuk spektrum target dengan faktor skala kurang dari 2 dan jika memungkinkan dapat dicari catatan gempa di Indonesia, sehingga hasil catatan gempa yang didapat bisa lebih baik.

3. Untuk penelitian berikutnya dapat dicari database yang mengikutsertakan catatan gempa pada zona subduksi karena pada Pulau Jawa juga terdapat zona subduksi. 


\section{DAFTAR PUSTAKA}

Abrahamson, N.A. "Non-stationary spectral matching." Seismological Research Letters, 1992: 30.

Badan Standarisasi Nasional. Tata Cara Perencanaan Ketahanan Gempa Untuk Struktur Bangunan Gedung dan Non Gedung. Jakarta: BSN, 2012.

Bolt, B.A and N.J Gregor. "Synthesized strong ground motions for the seismic condition assessment of the eastern portion of the San Francisco Bay Bridge.” Report UCB/EERC-93/12, 1993.

Chopra, Anil K. Dynamics of Structures. Boston: Prentice Hall, 2011.

Computer and Structures Inc. CSI Analysis Reference Manual. California, USA, 2016.

FEMA 451B. NHERP Recommended Provisions for New Buildings and Other Structures: Training and Instructional Materials. Washington, D.C., 2007.

PEER. PEER Ground Motion Database. Tersedia di ngawest2.berkeley.edu ( 5 Juni 2020).

PUSKIM. Desain Spektra Indonesia. Tersedia di puskim.pu.go.id/Aplikasi/desain_spektra_indonesia_2011 (25 Mei 2020).

Seismosoft. Seismosoft's Suite of Earthquake Tools. Italia, 2018.

Tim Pusat Studi Gempa Nasional. Peta Sumber dan Bahaya Gempa Indonesia Tahun 2017. Jakarta: Kementrian Pekerjaan Umum dan Perumahan Rakyat, 2017. 